\title{
ACTUALIDAD CONSTITUCIONAL EN EEUU (2006/2007). LA CONSTITUCIÓN FUERA DE LA CONSTITUCIÓN
}

\author{
MARCOS CRIADO DE DIEGO \\ Profesor Titular de Derecho Constitucional \\ Universidad de Alicante \\ ANTONIO DE CABO DE LA VEGA \\ Catedrático de Derecho Constitucional \\ Universidad Complutense de Madrid
}
SUMARIO
I. La constitución fuera de la Constitución: el "giro teórico" en los estudios de dere- cho en los EEUU y la perspectiva sus- tancial
II. Hamdan y la Military Commissions Act de 2006
III. Jurisprudencia del Tribunal Supremo

Retomamos en estas páginas la panorámica sobre actualidad constitucional en EEUU incluyendo los años 2006 y 2007, para cubrir así la falta de panorámica en el volumen anterior de la revista. La reflexión específicamente constitucional sigue dirigiendo su atención a las consecuencias del estado de excepción conocido como war on terror, declarado por el presidente George Bush jr. tras el 11 de septiembre de 2001, particularmente sobre la decisión del Tribunal Supremo en Hamdan v. Rumsfeld ${ }^{1}$ y la respuesta legislativa a esta decisión a través de la Miltary Commissions Act de 2006 (MCA)².

1126 S. Ct. 2749 (2006).

2 Pub. L. No. 109-366, 120 Stat. 2600 (2006) (codificada en distintas secciones de los epígrafes 10,18 y 28 del U.S. Code). 
Concretamente, Hamdan reconoce: a) la vigencia de la Constitución estadounidense en supuestos que se encuentran territorialmente fuera de los EEUU (como son los casos de los presos en Guantánamo y en distintas bases estadounidenses situadas en suelo extranjero); b) la jurisdicción de las cortes federales en materia de habeas corpus para revisar estas situaciones de privación de libertad; $c$ ) la aplicación del art. III común de las Convenciones de Ginebra a estos casos y $d$ ) la falta de competencia del Presidente para sustituir las cortes militares reguladas en el Código de Justicia militar por comisiones militares.

Respondiendo al intento del Tribunal Supremo de constitucionalizar la situación de los detenidos en el marco de la war on terror, la MCA priva de competencia a cualesquiera tribunales para conocer de los escritos de habeas corpus presentados por combatientes enemigos extranjeros ${ }^{3}$. Esta previsión ha servido de base para una reciente decisión del D.C. Circuit que afirma la inaplicación de las garantías constitucionales a la base naval de Guantánamo ${ }^{4}$, lo que parece contradictorio tanto con la decisión del Tribunal Supremo en Hamdan como con el objetivo del habeas corpus y con el tratamiento como una institución de common law que le ha dado el propio Tribunal a lo largo de su historia ${ }^{5}$. Se discute, por una parte, si estamos ante una mera reforma legislativa del habeas corpus legal contenido en el 28 U.S.C. \2241 que deja a salvo la aplicación del habeas corpus constitucional, o si, por el contrario estamos ante una aplicación de la Suspension Clause del art. I de la Constitución estadounidense ${ }^{6}$ que permite la suspensión del habeas corpus constitucional en situaciones de excepción. Por otro lado, admitiendo esta última interpretación, se discute el alcance de la suspensión: particularmente si supone una autorización de la detención ilegal o si, por el contrario, deja a salvo otros remedios judiciales como la indemnización.

En términos generales, un importante sector doctrinal niega que se esté luchando una guerra contra el terror, reconducible a los parámetros constitucionales de la excepcionalidad, sino que ello sirve como pantalla de un proceso de signo conservador de reforma "extraconstitucional" (o extracanónica, según una terminología consolidada en EEUU) de la Constitución, que habría sido iniciado por la mayoría republicana durante la doble presidencia de George Bush jr. El objetivo consistiría en poner fin a la lectura liberal de la Constitución por parte de los jueces y, con ella, a la progresiva inclusión en el acervo constitucional estadounidense de los derechos de igualdad formal (representados por los Black Codes de los años 60 del siglo xx) y material (contenidos en las leyes del New Deal y que se conocen como second bill of

3 Cfr. MCA \ 7, 28 U.S.C. \2241(e) (2006).

4 Boumediene v. Bush, 476 F.3d 981 (D.C. Cir. 2007), 127 S. Ct. 1478 (2007).

5 Cfr. D. Michael, "Recent Developments. The Military Commissions Act of 2006", en 44 Harvard Journal on Legislation, 2007, págs. 480-486.

6 Cfr. Art. I, $\$ 9$, cl. 2, de la Constitución de EEUU. 
rights) ${ }^{7}$, así como ciertos derechos de reconocimiento jurisprudencial (como la no segregación racial en las escuelas o la despenalización del aborto).

\section{LA CONSTITUCIÓN FUERA DE LA CONSTITUCIÓN: EL «GIRO TEÓRICO" EN LOS ESTUDIOS DE DERECHO EN LOS EEUU Y LA PERSPECTIVA SUSTANCIAL}

\section{EL «GIRO TEÓRICO» EN LOS ESTUDIOS DE DERECHO EN LOS EEUU}

En este apartado pretendemos dar noticia de ciertas tendencias doctrinales que encontramos en los trabajos publicados durante los años $2006 \mathrm{y}$ 2007 y que, a pesar de su heterogeneidad, tienen en común una perspectiva material en el estudio de la Constitución, una intencionalidad que concibe la actividad doctrinal en términos de lucha por el derecho y no de mero análisis formal, y una fuerte revalorización del trabajo teórico en detrimento del meramente dogmático o descriptivo.

Hamdan ha supuesto un espaldarazo a los representantes de este "giro teórico" que se está produciendo en las escuelas de derecho estadounidense y que está representado por profesores que se especializan en áreas que no tienen una relevancia obvia en las actividades profesionales de los estudiantes posteriores a la licenciatura ${ }^{8}$. El Caso se desarrolló a partir de un artículo doctrinal de los profesores Kayhal y Tribe , que actuaron como counsels of record en el proceso; de diversas teorías doctrinales de carácter teórico que fueron fundamentales en su construcción y argumentación: teorías relativas a la privación legislativa de competencia judicial (judicial-stripping) ${ }^{10}$; la teoría del profesor Carlos Vazquez sobre uso defensivo de los tratados internacionales como alternativa a la self-execution ${ }^{11}$ y las teorías de Derek Jink sobre la aplicabilidad de las Convenciones de Ginebra ${ }^{12}$.

La referencia expresa al art. 3 común de las Convenciones de Ginebra por parte de la pluralidad en Hamdan (aunque en tanto que está integrado 2006.

7 Vid. B. AcKerman, Before the Next Attack: Preserving Civil Liberties in an Age of Terrorism,

8 Sobre la importancia de Hamdan a este respecto, vid. N.K. KAYHAL, "Hamdan v. Rumsfeld: The Legal Academy Goes to Practice", en 120 Harvard Law Review, 2006; una descripción de este "giro teórico" puede encontrarse en K. ABRAMSON, "Art for a Better Life: A New Image for American Legal Education", en 2006 BYU Educ. and L. J., págs. 283-284.

9 N. K. KaYhal y L. H. Tribe, "Waging War, Deciding Guilt: Trying the Military Tribunals", en 111 Yale Law Journal, 2002, págs. 1259 ss.

10 Vid. H.H. HART JR., “The Power of Congress To Limit the Jurisdiction of Federal Courts: An Exercise in Dialectio", en 66 Harvard Law Review, 1953, págs. 1362 ss.; A. R. AmAR, "A Neo-Federalist View of Article III: Separating the Two Tiers of Federal Jurisdiction", en 65 B.U.L. Rev., 1985, págs. 205 ss.

11 Vid. C. M. VAzQuez, "Treaty-Based Rights and Remedies of Individuals", en 92 Columbia Law Review, 1992, págs. 1082 ss.

12 Vid. D. JINK, «The Applicability of the Geneva Conventions to the 'Global War on Terrorism', en 46 VAJ Int'l L., 2005, págs. 165 ss. 
en el Código de Justicia Militar) supone también un espaldarazo a la opinión mayoritaria manifestada por el Tribunal Supremo en Roper $v$. Simmons ${ }^{13}$, abre una puerta jurisprudencial a la superación del monismo estadounidense y respalda la reciente tendencia de los jueces del common law a utilizar los tratados internacionales en materia de derechos humanos como instrumentos interpretativos, aún en los casos en que no existe una implementación a través de normas internas ${ }^{14}$.

Otro ejemplo de la importancia que la perspectiva sustantiva de la Constitución está cobrando en los EEUU, es el análisis jurisprudencial del curso judicial de 2006 en la Harvard Law Review, a cargo de Martha C. Nussbaum ${ }^{15}$. La metodología adoptada consiste en analizar la jurisprudencia a partir de su idoneidad para garantizar la "libertad real y sustancial" de los ciudadanos, que da una perspectiva normativa de acercamiento al papel desarrollado por la administración, a la determinación de los objetivos de la Constitución y a la naturaleza de los derechos básicos constitucionales, denominada "capabilities approach". Se trata de una perspectiva de análisis heredada del trabajo de Amartya Sen, Development as Freedom (1999) ${ }^{16}$, y de la labor desarrollada por el Proyecto de Naciones Unidas para el Desarrollo en la elaboración de índices (de desarrollo humano, de igualdad de género...) que, por un lado, tienen un aspecto normativo (de obligar a los gobiernos a poner el desarrollo económico al servicio de la libertad y autonomía de sus ciudadanos) y, por otro, un aspecto de medición objetiva de la efectiva realización de ese objetivo. Se trata por tanto de una metodología destinada a la crítica constitucional de la labor de los jueces y no a la creación de categorías descriptivas en el análisis de la jurisprudencia, así como a establecer criterios sustantivos de juicio de esa labor según una concepción normativa de los objetivos constitucionales ${ }^{17}$.

13543 U.S. 551 (2005).

14 Vid. M. A. WATERS, "Reeping Monism: The Judicial Trend Toward Interpretative Incorporation on Human Rights Treaties", en 107 Columbia Law Review, 2007, págs. 628 ss, que analiza seis años de tratamiento judicial de la material por parte del Tribunal Supremo de EEUU y otras jurisdicciones de common law; sobre la plena compatibilidad con el art. III de la Constitución de EEUU de la supranational judicial review atendiendo a la práctica histórica y la doctrina en vigor, vid. H. P. Monaghan, "Article III and Supranational Judicial Review", en Idem, págs. 833 ss. En general, puede consultarse P. SCHIFF BERMAN, "Global Legal Pluralism", en 80 Southern California Law Review, 2007, págs. 1155 ss, el Congreso sobre Global Costitutionalism, celebrado los días 16 y 17 de febrero de 2007 en la Stanford Law School, publicado en el volumen 59 de la Stanford Law Review, 2007, págs. 1153 ss y R. R. ZubaTY, "Foreign Law and the U.S. Constitution: Delimiting the Range of Persuasive Authority", en 54 UCLA Law Review, 2007, págs. 1413 ss.

15 Vid. M. C. Nussbaum, "Constitution and Capabilities: 'Perception' Against Lofty Formalism", en 121 Harvard Law Review, n. 1, 2007.

16 Vid. A. SEN, Development as Freedom, Oxford, Oxford University Press, 1999.

17 La profesora Nussbaum comenzó esta perspectiva de estudio en el año 2000, con el libro Woman and Human Development: The Capabilities Approach, Cambridge, Cambridge University Press, 2000, a los que siguieron Id, "Capabilities as Fundamental Entitlements: Sen and Social Justice", en 9 Feminist Economics, 2003, págs. 33 ss. e Id., Frontiers of Justice: Disability, Nationality, Species Membership, Cambridge, The Belknap Press of Harvard University, 2006. 


\section{EL MOVIMIENTO POR LOS DERECHOS CIVILES DE LOS INMIGRANTES}

En esta misma línea de análisis podemos incluir los trabajos tendentes a relacionar la política en materia de inmigración del gobierno Bush jr. con el surgimiento de un movimiento social por los derechos de los inmigrantes ${ }^{18}$. En la primavera de 2006, cientos de miles de inmigrantes y ciudadanos estadounidenses marcharon por toda la Federación reclamando derechos para los extranjeros, conformando un movimiento sin precedentes en los EEUU. En un primer momento, el objetivo de las marchas consistía en reaccionar frente a un proyecto de ley que imponía sanciones criminales a las personas que otorgaran ayuda humanitaria a inmigrantes indocumentados ${ }^{19}$.

En un segundo momento, se solicitaban leyes que permitieran a los inmigrantes indocumentados regularizar su situación y se denunciaba el clima anti-inmigración que existía en EEUU después del 11 de septiembre. En el verano de 2006 ya existían signos de debilitamiento del movimiento, y las marchas del día del trabajo de 2006 movilizaron a un número muy inferior de gente que las convocadas unos meses antes. Esta desmovilización puede deberse a que la política de inmigración ha demostrado ser muy volátil en un año electoral. El Congreso ha fracasado a la hora de dictar cualquier reforma general de la legislación en inmigración. En cambio, el Congreso sí ha aprobado una ley que autoriza la extensión de la verja en la frontera mejicana $^{20}$.

La importancia del movimiento por los derechos de los inmigrantes no se encuentra sólo en la capacidad de resistencia ciudadana frente a reformas regresivas y su capacidad de presión para conseguir garantías jurídicas para una población altamente vulnerable, sino también en la posibilidad de crear coaliciones interétnicas para superar formas de discriminación de las minorías raciales entre sí. El análisis de la conflictividad laboral en los EEUU en 2006, revela que el patrón de discriminación del blanco hacia el resto de razas, que es el que recoge la legislación antidiscriminación estadounidense, se completa de un tiempo a esta parte con la discriminación laboral del latino hacia el afroamericano, para la que no existen previsiones legales específicas ${ }^{21}$.

18 Vid., en general, K. R. Johnson y B. O. Hing, "The Immigrant Rights Marches of 2006 and the Prospects for a New Civil Rights Movement, en 42 Harvard Civil Rights-Civil Liberties Law Review, 2007, págs. 95 ss.

19 Border Protection, Antiterrorism and Inmigration Control Act of 2005, H.R. 4437, $109^{\text {th }}$ Cong. I\$ 203, 205 (2005), conocida por el nombre de su proponente como Sensenbremmer bill. Vid. D. Thomas O'Rourke, "Recent Development. Good Samaritarians Beware: The Sensenbremmer-King Bill and Assistance to Undocumented Inmigrants, en 9 Harvard Latino Law Review, 2006, págs. 195 ss.

20 Secure Fence Act of 2006, Pub. L. No. 109-367, 120 Stat. 2638 (2006). Una crítica a la ley con propuestas para su reforma, puede consultarse en K. R. JoHnson, Opening the Floodgates: Why America Needs to Rethink. Its Borders and Immigration Law, Nueva York-Londres, New York University Press, 2007.

21 Vid. T. K. HeRnÁNDEZ, "Latino Inter-Ethnic Employment Discrimination and the 'Diversity' Defense", en 42 Harvard Civil Rights-Civil Liberties Law Review, 2007, págs. 259 ss. 


\section{LA CONSTITUCIÓN FUERA DE LA CONSTITUCIÓN}

Entre el 3 y el 5 de octubre de 2006, el profesor Bruce Ackerman impartió en la Facultad de Derecho de Harvard las Oliver Wendell Holmes Lectures, bajo el título de "The Living Constitution" "2 . En estas lecciones, el profesor Ackerman parte del hecho que los debates actualmente existentes en la sociedad norteamericana sobre aborto $^{23}$ y religión, sobre federalismo y sobre los poderes extraordinarios del Presidente, forman parte de un movimiento conservador impulsado por el Partido Republicano para cambiar la Constitución, siguiendo el guion de higher lawmaking que se elaboró durante el New Deal. Es decir, estarían buscando realizar reformas legislativas que materialmente reformen la regulación constitucional, al tiempo que se aseguran el control del Tribunal Supremo para que elabore sentencias que funcionen como precedentes ratificando la interpretación constitucional contenida en la legislación.

El profesor Ackerman recupera así dos de las tesis principales de sus dos volúmenes sobre historia constitucional estadounidense We the People: Foundations (1991) y We the People: Transformations (1998), que ya comentamos en estas páginas hace algunos años ${ }^{24}$ : a) Que el procedimiento de reforma constitucional del art. $\mathrm{V}$ de la Constitución, que requiere su aprobación por las 2/3 partes de las Cámaras y por las legislaturas de las 3/4 partes de los Estados, es un procedimiento que no se corresponde con la actual conciencia de nación unitaria que tienen los EEUU, al dar un papel determinante a los estados que hace prácticamente inviable la reforma constitucional ${ }^{25}$; b) que dada esta falta de correspondencia entre conciencia nacional y criterio confederal de reforma constitucional, desde hace setenta y cinco años la mayor parte de las reformas de la Constitución de EEUU son reformas de hecho, a través de un procedimiento consistente en la renovación continuada del mandato electoral que los electores otorgan a un movimiento político-partidista, durante el tiempo necesario para hacerse con el control tanto del poder legislativo como del Tribunal Supremo ${ }^{26}$.

22 Vid. B. AcKerman, "2006 Oliver Wendell Holmes Lectures. The Living Constitution", en 120 Harvard Law Review, 2007, págs. 1737 ss.

23 Por ejemplo, la reacción conservadora frente a la admisión jurisprudencial del aborto y el intento de "tumbar" legislativamente Roe v. Wade (410 U.S. 113 (1973)) puede consultarse en R. Post y R. SIEgel, "Roe Rage: Democratic Constitutionalism and Backlash", en 42 Harvard Civil Rights-Civil Liberties Law Review, 2007, págs. 373 ss.

24 Vid. B. ACKerman, We The People: Transformations, Cambridge, The Belknap Press of Harvard University, 1998 e Id., We The People: Foundations, Cambridge, Harvard University Press, 1991. El comentario se encuentra en M. Criado de Diego y A. de Cabo de la Vega, "La actualidad constitucional en EEUU en 1999", en Teoría y Realidad Constitucional, 5, 2000, págs. 266-271.

25 Cfr. B. Ackerman, We The People: Transformations, cit., págs. 403-418; B. ACKerman, "The Living Constitution", cit., págs. 1743-1750.

26 Cfr. B. ACKerman, "The Living Constitution", cit., págs. 1757-1765 y passim. Para una descripción del modelo elaborado durante el New Deal, cfr. Id., We The People: Transformations, cit., págs. 255-382. Una nueva aproximación, con consideraciones sobre la necesidad de un criterio común de referencia establecido en Marbury $v$. Madison y análisis sobre las crisis electorales de la época republicana, puede consultarse en B. ACKERMan, The Failure of the Founding Fathers: Jef- 
El profesor Ackerman parte de la existencia actualmente en los EEUU de un canon oficial, compuesto por el texto constitucional de 1787 y sus enmiendas formales, que forma el cuerpo de textos que la teoría convencional coloca en el centro de la cultura legal estadounidense. Sin embargo, existiría un abismo entre este canon oficial y la autoconciencia nacional del pueblo estadounidense $^{27}$. La profesión jurídica ha intentando salvar este abismo con lo que el profesor Ackerman llama un canon operativo que otorga a los hitos legislativos (landmark statutes) y a los superprecedentes judiciales un papel central en el debate constitucional, con la idea de incorporar así las realizaciones constitucionales de todas las generaciones de estadounidenses desde 1776 hasta el siglo $\mathrm{xx}^{28}$.

La idea de "supreprecedente" comienza a hacerse familiar en la doctrina y existe una conciencia bastante extendida de que el Tribunal Supremo tiene una obligación institucional de reconocer que los «superprecedentes" cristalizan cuestiones estables de la tradición constitucional norteamericana y que no deben ser derogados (overrruled) ni ignorados en el desarrollo de la interpretación doctrinal ${ }^{29}$. En este sentido, los "superprecedentes" actúan como enmiendas formales en el canon operativo ${ }^{30}$. Sin embargo, no ha ocurrido lo mismo con los hitos legislativos, a pesar de que a lo largo del siglo xx se ha producido una importante doctrina que intenta modificar el tratamiento escéptico que la tradición del common law dispensa a la legislación y que aboga por concebir las principales leyes en palabras del Juez Stone, como «una fuente de Derecho y una premisa del razonamiento legal ${ }^{31}$. Según el profesor Ackerman, estos tipos de leyes existen, como podrían ser la Social Security $A c t^{32}$ y las leyes de derechos civiles de los años sesenta del siglo pasado (Civil Rights Act de 1968, Voting Rights Act de 1965; y Civil Rights Act de 1964).

La intención final del profesor Ackerman consiste en crear un sistema de análisis y discusión que permita construir el canon común de referencia que exige la constitutional judicial review tal y como quedó establecida en

ferson, Marshall, and the Rise of Presidential Democracy, Cambridge, The Belknap Press of Harvard University, 2005, págs. 16-35, 77-93 y 224-244. La aplicación del modelo y sus variantes a la época de los derechos civiles se encuentra en B. ACKerman, "The Living Constitution", cit., págs. $1757-1793$.

27 Cfr. B. Ackerman, "The Living Constitution", cit., págs. 1750.

28 Cfr. Idem., págs. 1751.

29 Entre lo más reciente, vid. M. J. Gerhard, "Super Precedent", en 90 Minnesota Law Review, 2006, págs. 1204 ss. Una aplicación práctica de cuanto dicho puede verse en la crítica de los profesores Eric A. Posner y Cass R. Sustein a Hamdan por no haber aplicado la doctrina Chevron: "Chevronizing Foreingn Relations Law", en 116 Yale Law Journal, 2007, págs. 1170 ss.

30 Cfr. B. Ackerman, "The Living Constitution", cit., págs. 1752.

31 Cfr. H. F. STOne, "The Common Law in the United States", en 50 Harvard Law Review, 1936, p. 16. Son ya clásicos en esta materia G. Calabresi, A Common Law for the Age of Statutes, Cambidge-Londres, Harvard University Press, 1982 y J. Waldron, The Dignity of Legislation, Cambridge, Cambridge University Press, 1999. La idea de la existencia de normas legislativas constitutivas del orden político, pero fuera de la Constitución escrita puede consultarse en W. N. EsKRIDGE JR. y J. FEREJOHN, "Super-Statutes», en 50 Duke Law Journal, 2001, págs. 1215 ss.

32 Pub. L. No. 74-271, 49 Stat. 620 (1935) 
Marbury $v$. Madison. Pero la cuestión que no resuelve es si dicho sistema permite incorporar al canon tanto los derechos de creación legislativa (particularmente los derechos sociales y civiles) como ciertos derechos de creación jurisprudencial (como la no segregación en las escuelas o el derecho al aborto), para protegerlos de la reacción conservadora o si, por el contrario, tales derechos quedan al albur de mayorías socialmente sostenidas en el tiempo ${ }^{33}$.

\section{HAMDAN Y LA MILITARY COMMISSIONS ACT DE 2006}

\section{HAMDAN V.RUMSFELD}

En 2006, el Tribunal Supremo concedió habeas corpus a Salim Ahmed Hamdan, un nacional Yemení detenido en la Base de Guantánamo. Hamdan fue capturado por fuerzas militares en Afganistán y, tras permanecer detenido durante dos años, le fue imputado el delito de conspiración para delinquir enjuiciable por una comisión militar ${ }^{34}$.

La Corte, en la ponencia del juez Stevens, determinó que la comisión militar prevista para enjuiciar a Hamdan era ilegal por dos motivos. En primer lugar, el Tribunal establece que la comisión no ha sido autorizada de manera expresa por el Congreso ${ }^{35}$. Como la Constitución no regula comisiones militares, el Tribunal dirige su mirada al common law en búsqueda de argumentos que respalden la autorización ${ }^{36}$. En este caso, el Tribunal encuentra que las comisiones previstas para juzgar a Hamdan no satisfacen dos de las cuatro precondiciones del common law para ejercer la jurisdicción militar ${ }^{37}$. Por un lado, los hechos que se alega cometió Hamdan no ocurrieron en escenario de guerra o durante el conflicto armado ${ }^{38}$. Segundo, el delito imputado, conspi-

33 Para una crítica a la indefinición de los elementos que componen el canon aplicable en la teoría de Bruce Ackerman, vid. E. A. Young, "The Constitution outside the Constitution", en 117 Yale Law Journal, 2007, págs. 408 ss.

34 Ver Hamdan v. Rumsfeld, 126 S. Ct., 2759.

35 Idem., 2774-2775. El Tribunal declara que ni la Detainee Treatment Act (DTA), Pub. L. No. 109-148, 119 Stat. 2680 (codificada en el 10 U.S.C. \$948r(c)-(d) (2006)), ni la Authorization to Use Military Force (AUMF), Pub. L. No. 107-44, 115 Stat. 224 (2001), contienen en su letra una autorización a establecer comisiones militares para juzgar enemigos combatientes ilegales.

36 Idem., 2773-2775.

37 Idem., 2777-2779, citando expresamente a W. WInTHrop, Military Law and Precedents (2 ed. rev 1920), Buffalo (NY), W.S. Hein \& Co, 2000, págs. 836-838: Primero, una comisión militar solo tiene jurisdicción sobre delitos cometidos en escenario de guerra; segundo, el delito imputado debe haberse cometido durante el periodo de guerra; tercero, sólo pueden juzgarse soldados enemigos sospechosos de violaciones del derecho de guerra así como a los miembros del propio ejército; cuarto, una comisión militar únicamente tiene jurisdicción para juzgar violaciones del derecho y costumbres de guerra competencia de los tribunales militares, así como incumplimientos de órdenes o regulaciones militares sobre las que los inculpados no puedan ser legalmente enjuiciados por una corte marcial bajo el derecho de guerra.

38 Hamdan, cit, 2777-2779. 
ración, no es una violación del derecho de guerra y por tanto no puede ser enjuiciado por una comisión militar ${ }^{39}$.

En el art. 21 del Uniform Code of Military Justice (UCMJ) ${ }^{40}$, el Congreso expresamente establece que las comisiones militares tienen jurisdicción para juzgar delitos contra las leyes de la guerra. Puesto que los límites del cuerpo jurídico citado no son claros, el Tribunal afirma que al menos abarca las Convenciones de Ginebra ${ }^{41}$. Las comisiones militares establecidas para juzgar a Hamdan no satisfacen los requisitos del art. 3 común de las Convenciones de Ginebra $^{42}$, porque no establecen "todas las garantías judiciales que han sido reconocidas como indispensables por los pueblos civilizados", condición que la tercera Convención impone a sus signatarios ${ }^{43}$. Específicamente, el Tribunal señala que la comisión puede excluir al reo y a su defensor de la vista ${ }^{44}$ y que incluso puede admitir, bajo un juicio de relevancia, pruebas de referencia y pruebas obtenidas bajo coerción ${ }^{45}$. El Tribunal también establece que juzgar a Hamdan por conspiración viola el art. 3 común de las Convenciones de Ginebra, toda vez que "la conspiración rara vez ha sido juzgada en este país por una comisión militar, si lo ha sido alguna, y no aparece en los principales tratados sobre derecho de guerra ${ }^{46}$.

\section{LA RESPUESTA A HAMDAN v. RUMSFELD}

Inmediatamente después de que el Tribunal Supremo fallara que las comisiones militares de Guantánamo carecían de autorización legal y eran por tanto inconstitucionales, la Casa Blanca presentó una propuesta de ley al Congreso para remediar el problema y para otorgar al ejecutivo poderes adicionales que la propia Casa Blanca consideraba necesarios. Después de dos meses de negociaciones entre la Administración Bush y algunos miembros renuentes de su propio partido, el Senado aprobó la MCA el 28 de septiembre de 2006 que fue firmada como ley por el Presidente el 17 de octubre.

Respondiendo a la falta de autorización legislativa expresa señalada por Hamdan, la MCA otorga al Presidente la autoridad para establecer comisiones militares para combatientes enemigos ilegales ${ }^{47}$. Pero también intenta solucionar el segundo defecto de las comisiones militares señalado en Hamdan:

39 Ibid., p. 2779.

4010 U.S.C. $\$ 821$ (2006)

41 Hamdan, cit., 2794.

42 Vid. Convención de Ginebra relativa al Tratamiento de los Prisioneros de Guerra, adoptada el 12 de agosto de 1949.

43 Hamdan, cit., 2795-2798.

44 Idem., 2786 ("The accused and his civilian counsel may be excluded from, and precluded from ever learning what evidence was presented during, any part of the proceeding that either the Appointing Authority or the presiding officer decides to 'close'").

45 Idem., 2798.

46 Idem., 2780-2781.

47 MCA \3(a)(1), 10 U.S.C. \948b (b) (2006). 
que no satisfacían los estándares del art. 3 común de las Convenciones de Ginebra tal y como habían sido incorporados por el UCMJ. La MCA declara que la ley proporciona todas las "garantías judiciales que han sido reconocidas como indispensables por los pueblos civilizados a los efectos del artículo 3 común de las Convenciones de Ginebra" ${ }^{48}$.

Sin embargo, a pesar de esta declaración, el conjunto de derechos garantizados en la MCA están muy lejos del citado estándar. Por ejemplo, la MCA invierte la carga de la prueba de referencia introducida por la parte acusadora para establecer la culpabilidad del acusado ${ }^{49}$. Si el acusado no puede demostrar que la prueba de referencia es irrelevante o carente de valor probatorio, se declarará admisible.

La MCA tampoco tiene en cuenta las consideraciones del Tribunal Supremo relativas al uso de las declaraciones obtenidas bajo coerción ${ }^{50}$. La MCA establece que la declaración obtenida bajo coerción o la autoincriminación obligada es admisible siempre que un juez militar la encuentre relevante y le otorgue carácter probatorio ${ }^{51}$. Aunque el Tribunal Supremo declaró que el derecho de guerra que incorpora el $\mathrm{UCMJ}^{52}$ no reconoce el delito de conspiración, la MCA la reconoce como un delito sustantivo que puede ser castigado con la muerte ${ }^{53}$.

A pesar de desconocer varias de las garantías procesales señaladas por el Tribunal en Hamdan, la MCA supone algunas mejoras en otras áreas. Con algunas excepciones ${ }^{54}$, se reconoce el derecho de los detenidos a estar presentes en las sesiones de las comisiones militares así como a la asistencia técnica $^{55}$; igualmente, se les permitirá examinar y responder las pruebas de las

48 MCA $₫ 3(\mathrm{a})(1), 10$ U.S.C. $₫ 948$ b(f) (2006).

49 MCA $\$ 3(a)(1), 10$ U.S.C. $\$ 949^{\mathrm{a}}(\mathrm{b})(2)(\mathrm{E})(\mathrm{i})$-(ii) (2006). Esta regulación puede compararse con Hamdi $v$. Rumsfeld, 542 U.S. 507, 534 (2004), que sugiere la inconveniencia de un esquema similar de inversión de carga de la prueba respecto del estatus de posible combatiente enemigo.

50 Ver HAMDAN, cit., 2786-2787.

51 MCA $\int 3(\mathrm{a})(1), 10$ U.S.C. $₫ 948 \mathrm{r}(\mathrm{c})-(\mathrm{d})$, que establece que los artículos de la UCMJ relativos a la compulsory self-incrimination no son aplicables a los juicios con comisiones militares. La MCA distingue entre la coerción ocurrida antes y después de la entrada en vigor de la DTA. Como la DTA prohíbe el trato cruel, inhumano o degradante (DTA $₫ 1003$, 10 U.S.C. $₫ 948 \mathrm{r}$ (2006)), las declaraciones obtenidas después de su entrada en vigor y que se hayan conseguido mediante métodos de interrogatorio que impliquen esos métodos, son inadmisibles. Las declaraciones obtenidas antes de la entrada en vigor de la DTA en lo que el grado de coerción empleado esté en disputa, la MCA las declara susceptibles de admisión, siempre que la totalidad de las circunstancias doten a la declaración de relevancia o de suficiente valor probatorio y que se sirva mejor el interés de la justicia admitiendo la declaración como prueba.

52 HAMDAN, cit., 2774. El Tribunal establece que el art. 21 del UCMJ otorga al Presidente la autoridad de convocar comisiones militares bajo la expresa condición de que el Presidente y quienes se encuentran a sus órdenes respeten el derecho de guerra.

53 MCA $₫ 3(\mathrm{a})(1), 10$ U.S.C. $\$ 950 \mathrm{v}(\mathrm{b})(28)$ (2006).

54 Los detenidos no asistirán a las deliberaciones y votaciones de los miembros de la comisión (MCA \3(a)(1), 10 U.S.C. \949d(e) (2006)) y podrán ser excluidos si persisten en comportamientos que requieran la expulsión para asegurar la seguridad física de personas o para evitar la interrupción de la vista.

55 MCA $₫ 3(a)(1), 10$ U.S.C. $\$ 949$ c(b)(3) (2006). 
que haya conocido la comisión ${ }^{56}$; si la prueba está clasificada, el gobierno deberá entregar a la defensa un resumen desclasificado ${ }^{57}$.

\section{OTROS CAMBIOS PRODUCIDOS POR LA MCA}

Además de responder a Hamdan, la MCA limita la responsabilidad de los funcionarios públicos, permite la detención indefinida y despoja a los tribunales de su competencia para conocer de escritos de habeas corpus presentados por los privados de libertad.

La MCA establece los límites del interrogatorio permitido, definiendo la tortura a través de una lista de abusos ${ }^{58}$. Aunque la ley criminaliza los métodos de interrogatorio más extremos, al definir la tortura en términos muy reducidos, limita en exceso la responsabilidad de los agentes del gobierno que maltraten a los prisioneros ${ }^{59}$. El art. 3 común de la Convención de Ginebra obliga a que los signatarios penalicen los actos de tortura cometidos por sus agentes o funcionarios. La War Crimes Act responde a esta obligación otorgando acción penal a las personas que hayan sufrido "graves violaciones" de los estándares establecidos en el artículo 3 común ${ }^{60}$. Según la MCA, la tortura y el trato inhumano y degradante, son "graves violaciones" del art. 3 común, mientras que no lo son los tratos humillantes ${ }^{61}$. Es más, la definición de la MCA de trato inhumano o degradante está limitada a abusos extremos, como conductas que supongan un riesgo sustancial de muerte, desfiguración física, daño o pérdida de órganos $^{62}$. La definición legal de los abusos específicos prohibidos por el art. 3 común, es igualmente reducida: se reconoce que la violación y la agresión sexual son actividades coercitivas, pero no otras formas de sexo no consentido ${ }^{63}$.

Otro problema es que la MCA permite la detención indefinida. La ley exige que se notifique a los detenidos los cargos que se les imputan antes del juicio $^{64}$, pero no contiene disposición alguna sobre la celebración del juicio en un periodo determinado de tiempo, ni siquiera una obligación de que efectivamente se lleve a cabo ${ }^{65}$. La MCA afirma la inexistencia de límites de tiempo

56 MCA $₫ 3(\mathrm{a})(1), 10$ U.S.C. $₫ 949 \mathrm{a}(\mathrm{b})(1)(\mathrm{A})(2006)$

57 MCA \3(a)(1), 10 U.S.C. $\$ 949 d(f)(2)(A)(2006)$.

58 MCA \& $3(\mathrm{a})(1), 10$ U.S.C. $\$ 948 \mathrm{r}(\mathrm{b})(2006)$.

59 En este sentido, vid. la nota de prensa de Amnistía Internacional de 29 de septiembre de 2006, Amnesty Int'l, Military Commissions Act of 2006 - Turning Bad Policy into Bad Law, en http://web.amnesty.org/library/Index/engamr511542006.

6018 U.S.C. $\$ 2441(\mathrm{a}),(\mathrm{c})(1)(2006)$

61 MCA \6(b)(1)(B), 18 U.S.C. \2441(d) (2006).

62 MCA \$ 6, 18 U.S.C. $\$ 2441(\mathrm{~d})(2)(\mathrm{D})(2006)$.

63 MCA \6(b)(1)(B), 18 U.S.C. \$2441(d) (1)(G)-(H) (2006).

64 MCA $₫ 3(a)(1), 10$ U.S.C. $\$ 948 q(b)(2006)$.

65 Un análisis de la constitucionalidad de la detención indefinida puede consultarse en E. SEPPER, "The Ties That Blind: How the Constitution Limits the CIA's Actions in the War on Terror", en 81 New York Law Review, 2006, págs. 1805 ss; vid. también Hamdi v. Rumsfeld, cit., 520-521, donde el Tribunal Supremo establece que la AUMF no autoriza la detención indefinida para realizar interrogatorios. 
al proclamar que las disposiciones del UCMJ que garantizan el derecho de los acusados a un juicio rápido, no se aplican a las comisiones militares ${ }^{66}$.

Sin embargo, el contenido de la MCA que más interés doctrinal ha suscitado es la sección 7, que reforma la previsión legal del habeas corpus (28 U.S.C. \$2241), estableciendo que ningún tribunal tiene competencia para conocer de escritos de habeas corpus presentados por o en representación de extranjeros detenidos en los EEUU que hayan sido calificados como combatientes enemigos, o que estén a la espera de dicha calificación ${ }^{67}$. Esta previsión legal se aplica retroactivamente a todos los extranjeros detenidos desde el 11 de septiembre de $2001^{68}$, con lo que se impide de forma permanente a los extranjeros el derecho a que un cuerpo judicial independiente revise las razones, si es que existen, de su encarcelamiento.

\section{HABEAS CORPUS}

El derecho al habeas corpus nunca ha sido reconocido de manera continuada y consistente por la jurisprudencia a los extranjeros en los EEUU ${ }^{69}$. Desde los años 50 del siglo pasado, el Tribunal Supremo aplica una doctrina según la cual los derechos constitucionales se extienden sólo a aquellas personas que tengan una especial relación con los EEUU (la denominada "mebership approach" a las garantías constitucionales). Aunque el Tribunal Supremo nunca ha derogado (overruled) los casos en que se basa esta doctrina, de un tiempo a esta parte parece cobrar fuerza un análisis contextual del debido proceso que pone en relación los derechos reconocidos a los individuos con las cargas que esos derechos imponen al poder público. La aplicación de esta perspectiva a la situación de los detenidos en Guantánamo, pone de manifiesto que el derecho al habeas corpus debería aplicarse a los encarcelados en Guantánamo ${ }^{70}$.

Sin embargo, en febrero de 2007, el Tribunal federal de Apelaciones del Distrito de Columbia, en Boumediene v. Bush ${ }^{71}$, expresamente estableció

66 MCA $₫ 3(a)(1), 10$ U.S.C. $\$ 948 b(d)(1)(A)(2006)$

67 MCA $\$ 7($ a), 28 U.S.C. $\$ 2241($ e)(1) (2006). La definición de "combatiente enemigo ilegal" se encuentra en MCA $₫ 3(a)(1), 10$ U.S.C. $₫ 948 a(1)(A)(2006)$.

68 MCA $₫ 7(\mathrm{~b})$

69 Por ejemplo, en Johnson v. Eisentraiger, 339 U.S. 763, 780-781 (1950), donde el Tribunal Supremo conluye "that no right of writ of habeas corpus appears" para los extranjeros detenidos fuera de las fronteras de EEUU. Sin embargo, en Rasul v. Bush, 542 U.S. 466, 481 (2004) establece que la aplicación del procedimiento de habeas corpus a los detenidos en Guantánamo es consistente con la evolución histórica de la institución. En relación con la war on terror, vid. E. A. Wilson, "The War on Terrorism and "The Water's Edge»: Sovereignity, 'Territorial Jurisdiction' and the Reach of the U.S. Constitution in the Guantanamo Detainee Litigation", en 8 U. Pa.J. Const. L., 2006, págs. 165 ss y J. E. Pfander, "The Limits of Habeas Jurisdiction and the Global War on Terror", 91 Cornell Law Review, 2006, págs. 497 ss.

70 Cfr. Recent Developments. The Military Commissions Act of 2006, cit., p. 481.

71476 F.3d 981 (D.C. Cir. 2007), 127 S. Ct. 1478 (2007). 
que los derechos constitucionales no son de aplicación a los detenidos en Guantánamo, toda vez que la privación de competencia prevista en la MCA se aplica a las peticiones de habeas corpus de los detenidos y que dicha previsión no es una suspensión inconstitucional del proceso de habeas corpus.

El razonamiento del D.C. Circuit parte de la distinción entre dos formas de habeas corpus: una legal, prevista en 28 U.S.C. $₫ 2241$ (a la que afecta la MCA) y otra constitucional, conocida como "the privilege of the Writ of Habeas Corpus", que fue una de las (pocas) instituciones del common law expresamente reconocidas por los constituyentes de 1787 en el art. I $\$ 9$. Como es conocido, el common law se presenta, en su origen, como un derecho regio común a todos los súbditos y administrado a través de un sistema de tribunales nombrados por el rey, que imponen su decisión a las jurisdicciones locales. Para obtener la intervención del rey era necesario procurarse, previo pago, un writ en la Cancillería. El writ era sustancialmente una orden por la que el rey, dirigiéndose a uno de sus funcionarios locales, disponía que fuese hecha justicia y que fuese satisfecho el derecho por el cual se había procurado el writ mismo. Conforme se fueron separando los tribunales de common law del patronato regio, la única prerrogativa que se mantuvo fue el control sobre los órganos de justicia local, a través de los denominados prerogative writs, mediante los que los jueces itinerantes de la jurisdicción regia (justice in erie) pedían cuentas de su labor a las autoridades locales, verificaban la legalidad de su poder y la coherencia de su ejercicio conforme a los parámetros de la justicia central. Uno de estos writs era el habeas corpus, con el cual se solicitaba la presentación de un prisionero con el fin de verificar la legitimidad de su detención.

El hecho de que el habeas corpus de la sección 9 del art. I de la Constitución de EEUU incorpore una institución de common law con la extensión y el significado que en ese derecho se da, por un lado, y el hecho de que la reforma de la MCA afecte únicamente a la regulación legal de la institución, por otro, llevó a la defensa a plantear al D.C. Circuit la posibilidad de encontrar excepciones constitucionales a la aplicación de la disposición legal basadas en la experiencia y el objetivo de la institución en el common law ${ }^{72}$.

Como recientemente ha señalado Cary Federman, el habeas corpus constitucional "exists in speech and is celebrated as the 'great writ of liberty', but it has no content because it is so rarely used "73. Los casos en los que el Tribunal Supremo ha utilizado el habeas corpus en el contexto de la war on terror respaldan la afirmación, toda vez que Rasul v. Bush ${ }^{74}$, Hamdi v. Rumsfeld,

72 La idea del common law como una fuente de autoridad en ausencia de una previsión constitucional aplicable fue establecida por el Tribunal Supremo en U.S. v. Wong Kim Ark, 169 U.S. 649, 653-54 (1898) y ha sido ratificada recientemente en Hamdan v. Rumsfeld, cit., págs. 2773-2775.

73 Cfr. C. Federman, "The Body and the State: Habeas Corpus and American Jurisprudence", Nueva York, State University of New York Press, 2006, p. 165.

74542 U.S. 466, 473 (2004). 
Rumsfeld v. Padilla ${ }^{75}$ y Hamdan v. Rumsfeld se decidieron utilizando la sección 2241 del 28 U.S.C. y no la sección 9 del art. I de la Constitución.

En ausencia de un claro precedente, el D.C. Circuit centra su análisis en dos cuestiones: por un lado, si el writ of habeas corpus inglés se extendía a los no súbditos más allá de los dominios de la Corona y, por otro, si las garantías constitucionales se extienden a los extranjeros que no tienen conexiones sustanciales con los EEUU

El D.C. Circuit responde negativamente a la primera cuestión, en clara contradicción con lo establecido por el Tribunal Supremo en Rasul. En $A l$ Odah $v$. United States ${ }^{76}$ (proceso que en revisión por el Tribunal Supremo se convirtió en Rasul v. Bush) el D.C. Circuit declaró que el habeas corpus se extendía únicamente al territorio soberano. Puesto que la base de Guantánamo no es parte del territorio soberano de los EEUU, el tribunal declaró que carecía de jurisdicción para admitir el remedio del habeas corpus a los que allí se encontraban detenidos ${ }^{77}$.

En Rasul, el Tribunal Supremo casó Al Odab y rechazó expresamente el análisis del Tribunal de Apelación. El Tribunal Supremo concluyó que "later cases confirmed that the reach of the writ depend not on formal notions of territorial sovereignity, but rather on the practical question of the exact extent and nature of the jurisdiction or dominion exercised in fact by the Crow» ${ }^{78}$. Aplicando este estándar a Guantánamo, un territorio sobre el que "los EEUU ejercen jurisdicción plena y exclusiva", la Corte concluye que es «in very practical respect a United States territory ${ }^{79}$, por lo que la regulación del habeas corpus otorga competencia a los tribunales para conocer las solicitudes de habeas corpus presentadas contra las detenciones en Guantánamo.

Frente a este claro precedente que le obliga, el D.C. Circuit concluye que no existe ningún antecedente de common law que respalde que los extranjeros detenidos fuera del territorio soberano tengan derecho al habeas corpus $^{80}$ y además cita distintos tratados confirmando que el writ no se extiende a personas fuera de los dominios de la Corona ${ }^{81}$.

Junto al análisis de common law, el Tribunal afirma que los extranjeros encarcelados fuera del país no tienen derecho al habeas corpus porque los precedentes del propio tribunal y los del Tribunal Supremo sostienen que la Constitución no confiere derechos a extranjeros que no tengan propiedades o presencia en los EEUU ${ }^{82}$. El tribunal cita Johnson v. Eisentrager ${ }^{83}$ y United Sta-

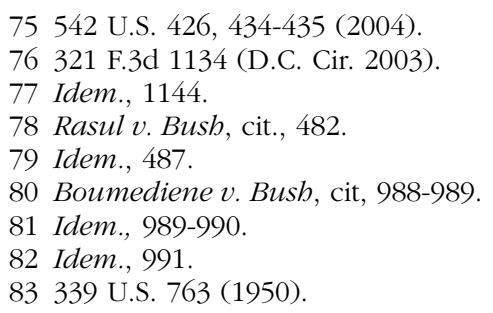


tes $v$. Verdugo-Urquidez $z^{84}$, casos que establecen lo que se conoce como "membership approach to Constitution", según la cual la protección constitucional se extiende sólo a aquellas personas cuyos contactos significativos y voluntarios con EEUU hayan creado "una conexión sustancial con nuestro país" ${ }^{85}$.

Sin embargo, este análisis del D.C. Circuit no parece consistente por varias razones. La cuestión que se está planteando aquí es determinar si y hasta qué punto la MCA debe ser declarada inconstitucional al impedir el ejercicio del habeas corpus a quién está constitucionalmente capacitado para ello. La MCA anula la competencia sobre cualquier escrito de habeas corpus presentado por un extranjero detenido como combatiente enemigo o en espera de esa calificación. La MCA define combatiente enemigo no como extranjeros capturados en el campo de batalla, sino como no ciudadanos sospechosos de uno o más delitos de los enumerados en la propia ley ${ }^{86}$. Por tanto, la falta de competencia no sólo se aplica a los extranjeros en el exterior sino a todos y cada uno de los 12 millones de residentes legales en los EEUU que sean sospechosos de esos delitos. El Tribunal Supremo ha establecido repetidamente que privar a los residentes permanentes extranjeros, la mayoría de los cuales tienen conexiones sustanciales con los EEUU, del derecho al habeas corpus viola la Suspension Clause . $^{87}$.

Más compleja es la cuestión de los no ciudadanos detenidos en Guantánamo, un área que no está bajo la soberanía de los EEUU pero que está bajo su jurisdicción y control, como se establece en Rasul v. Bush. En este sentido, aunque el Tribunal nunca ha derogado (overruled) la membership approach contenida en Eisentrager y en Verdugo-Urdiquez, ha afirmado sin lugar a dudas que esta perspectiva no es relevante en el caso de las comisiones militares de Guantánamo ${ }^{88}$. Además, la pluralidad concluyó en Hamdi que "las promesas constitucionales esenciales no pueden dejar de aplicarse ${ }^{89}$, mientras que otras pueden desplazarse en ciertos procedimientos diseñados para aliviar las cargas de un poder ejecutivo inmerso en un conflicto militar ${ }^{90}$. De esta suerte, como el Juez Green del D.C. District Court ha reconocido, el Tribunal Supremo ha establecido "an implicit, if not express, madate to uphold the existence of fundamental rights" de los que se encuentran detenidos en zonas bajo el control y la jurisdicción de los EEUU' ${ }^{91}$.

84494 U.S. 259 (1990).

85 Verdugo-Urquidez, cit., 260.

86 MCA \3(a)(1), 10 U.S.C. $\int 950 v(b)(2006)$.

87 Vid., por ejemplo, INS v. St. Cyr., 533 U.S. 289, 290 (2001) que establece "the Constitution's Suspension Clause, which protects the privilege of the habeas corpus writ, unquestionably requires some judicial intervention in deportation cases".

88 Rasul v. Bush, cit., 476, declarando que los actores en estos casos difieren respecto a los detenidos en Eisentrager en aspectos importantes.

89 Hamdi $v$. Rumsfeld, cit., 533

90 Idem., 533-534.

91 In re Guantanamo Detainee Cases, 355 F.Supp.2d 443, 461 (D.D.C. 2005). 
Desde una perspectiva distinta, cierta doctrina justifica esta respuesta legislativa sobre la base de que los funcionarios públicos poseen un especial conocimiento técnico para valorar el peligro para la seguridad nacional, conocimiento del que carecen los jueces ${ }^{92}$, lo que reclamaría un modelo de aproximación judicial a las previsiones legales y constitucionales que redujera al máximo la creatividad judicial y en el que los jueces actuaran como funcionarios públicos aplicando una ley (el llamado Agency Model frente al Common Law Model ${ }^{93}$.

Por último, otro sector doctrinal admitiendo que no estamos ante una mera reforma del habeas corpus legal, sino ante un auténtico ejercicio de la Suspension Clause, plantea la cuestión de qué consecuencias jurídicas tiene la suspensión por parte del Congreso del habeas corpus en casos de emergencia y en qué medida recorta las facultades judiciales para controlar las detenciones ilegales a través de otros mecanismos constitucionales como los derechos sustantivos $^{94}$. Es decir, se trata de contestar a la pregunta de si la suspensión del habeas corpus convierte una detención ilegal en legal, como a contrario se desprende de la opinión disidente del juez Scalia en Hamdi v. Rumsfeld $^{95}$, o, dicho en otros términos, si la suspensión equivale a una autorización del Congreso al ejecutivo para que proceda a realizar detenciones que, en otras circunstancias, serían ilegales.

El profesor Trevor W. Morrison adelantó una respuesta negativa, sobre la base de un estudio de la evolución histórica del habeas corpus en EEUU y en Inglaterra, que le lleva a dos conclusiones: en primer lugar, que la suspensión no afecta a la legalidad de la detención, por lo que ésta, vigente la suspensión, deberá producirse igualmente conforme a la ley; en segundo lugar, que una suspensión válida únicamente elimina "the privilege of the writ", entendido como un remedio particular frente a la detención ilegal, pero que deja vigentes todos los demás remedios endoprocesales posteriores a la detención, como puede ser la reclamación de una indemnización por daños ${ }^{96}$. (2007).

92 Cfr., en este sentido, E. A. Posner y A. Vermeule, Terror in the Balance, págs. 4-5

93 Sobre este punto, cfr. R. H. Fallon Jr. y D. J. Meltzer, «Habeas Corpus Jurisdiction, Substantive Rights, and the War on Terror", en 120 Harvard Law Review, 2007, págs. 2040-2045.

94 Sobre la Suspensión Clause en la época del war on terror, vid., B. Ackerman, "The Emergency Constitution", 113 Yale Law Journal, 2004, págs. 1029 ss y A. L. Tyler, "Is Suspension a Political Question?", en 59 Stanford Law Review, 2006, págs. 333 ss.

95 Cfr. Hamdi v. Rumsfeld, 542 U.S., 507 (2004), en 572 y 575-577 (Voto particular de Scalia). La opinión plural sostuvo que la Constitución permitía la detención de combatientes enemigos sin utilizar el procedimiento criminal ordinario, ya que existía la "posibilidad" de que el debido proceso pudiera ser cumplido a cabalidad por una comisión militar convenientemente autorizada antes que por un tribunal de los del art. III de la Constitución. Frente a ello, el juez Scalia argumentó que la suspensión del habeas corpus era el único procedimiento que permitía al ejecutivo evitar la obligación de presentar cargos contra un detenido o dejarlo libre y que, también, era el único procedimiento que podía convertir en legal una detención que, en el momento de producirse, era ilegal.

96 Cfr. T. W. Morrison, "Hamdi's Habeas Puzzle: Suspension as Authorization?", en 91 Cornell Law Review, 2006, págs. 411 ss. 
Respondiendo a este trabajo, David L. Saphiro argumenta que la jurisdicción de los tribunales en EEUU es de configuración legal por disposición del art. III de la Constitución de EEUU, y que es a la luz de este hecho como debe interpretarse la Suspensión Clause. En consecuencia, concluye, la competencia del Congreso no sólo supone la posibilidad de suspender la vigencia del habeas corpus frente a cualquier tribunal cuando así lo requiera la seguridad pública, sino que dicha competencia incluye impedir la aplicación judicial de los derechos y, por tanto, la revisión judicial de la propia medida legislativa a la luz de derechos sustantivos ${ }^{97}$. En una contrarréplica, el profesor Morrison sostiene que no es sólo a los jueces a quienes les corresponde la aplicación de la Constitución, sino que también los poderes ejecutivo y legislativo están obligados a cumplirla y ejecutarla, por lo que existen vínculos constitucionales sustantivos en la acción del Congreso de suspender la vigencia del habeas corpus, a cuyo amparo no puede sustraerse de sus obligaciones constitucionales y cuyo control corresponde a los órganos judiciales ${ }^{98}$.

\section{JURISPRUDENCIA DEL TRIBUNAL SUPREMO}

La presente revisión 99 analiza las decisiones del Tribunal Supremo con relevancia constitucional (constitucionales propiamente dichas y federales con relevancia constitucional) correspondientes al segundo año de la Corte Roberts. Aunque la tradición impone que los primeros ejercicios de cada Corte, sean períodos de transición en los que no se producen importantes cambios de rumbo jurisprudencial, ello sólo se cumple parcialmente para las sentencias estudiadas. Efectivamente, aunque no se han producido revocaciones ex-

97 Cfr. D. L. SAPHIRO, "Habeas Corpus, Suspension, and Detention: Another View", 82 Notre Dame Law Review, 2006, págs. 80-95; en la misma posición, cfr. R. H. Fallon Jr. y D. J. Meltzer, "Habeas Corpus Jurisdiction, Substantive Rights, and the War on Terror", cit., p. 2045.

98 Cfr. T. W. Morrison, "Suspensión and the Extrajudicial Constitution", en 107 Columbia Law Review, 2007, págs. 1533 ss.

99 Este comentario es continuación de la serie que incluye M. CRIADO y A. DE CABO, «La actualidad constitucional en Estados Unidos en 1997", Teoría y Realidad Constitucional, 1, 1998, págs. 247-252, Íd., "La actualidad constitucional en Estados Unidos en 1998", Teoría y Realidad Constitucional, 3, 1999, págs. 304-312; Íd., "La actualidad constitucional en Estados Unidos en 1999", Teoría y Realidad Constitucional, 5, 2000, págs. 282-286; Íd., "La actualidad constitucional en Estados Unidos en 2000", Teoría y Realidad Constitucional, 7, 2001, págs. 323-430; Íd., "La actualidad constitucional en Estados Unidos en 2001", Teoría y Realidad Constitucional, 10-11, 2002, págs. 647-661; Íd., "El fin del grantismo?: La actualidad constitucional en EEUU en 2002", Teoría y Realidad Constitucional, 12-13, 2003, págs. 524-531; Íd., "A vueltas con la rama menos peligrosa: La actualidad constitucional en EEUU en 2003", Teoría y Realidad Constitucional, 14, 2004, págs. 468-475; Íd., "Whose Voice?: La actualidad constitucional en EE.UU. en 2004", Teoría y Realidad Constitucional, 16, 2005, págs. 425-431; Id., "How Democratic is the American Constitution? La actualidad constitucional en EE UU en 2005", Teoría y Realidad Constitucional, 18, 2006, págs. 393-396, a la que debe remitirse para la comprensión de algunas tendencias jurisprudenciales. Se sigue, por lo demás, la técnica expositiva aplicada en la misma. 
presas de precedentes, algunas sentencias apuntan hacia una Corte con un enfoque claramente conservador y formalista que podría continuar la labor de "desustanciación" constitucional de su predecesora. Por otra parte, la Corte aparece notablemente dividida, confiando para algunas de sus decisiones más importantes en el voto de su Presidente. Aunque muy diferentes en carácter y contenido, las dos sentencias más importantes son, probablemente, Parents Involved in Community Schools v. Seattle School District No. $1^{100}$ por su, por decir lo menos, ambigua relación con uno de los casos paradigmáticos de la jurisprudencia sobre integración racial (Brown v. Board of Education ${ }^{101}$ ), y Zuni Public School Districts No. 89 v. Department of Education ${ }^{102103}$ por el posible cambio jurisprudencial en la aplicación de la Doctrina Chevron.

\section{Relativas a la TAKings Clause (EXPropiación).}

En Wilkie v. Robbins ${ }^{104}$ la Corte ha introducido una nueva restricción a la posibilidad de reclamar indemnización por violación de derechos constitucionales por parte de un funcionario federal - también en ausencia de una norma federal autorizándolos (es decir, de creación pretoriana) - que estableciera en Bivens $v$. Six Unknown Named Agents of Federal Bureau of Narcotics $^{105}$. En el presente caso, Frank Robbins adquirió un terreno sobre el que el Bureau of Land Managment (BLM) tenía contratado un derecho de paso previo que, al no haber sido registrado en su momento, quedaba anulado como consecuencia de la compraventa. El BML comenzó una serie de acciones "ofensivas y, en ocasiones, ilegales" "106. Una vez fracasadas las vías administrativas de defensa de sus derechos, Robbins presentó una demanda de indemnización contra los funcionarios por violación de sus derechos de la Cuarta y Quinta Enmiendas, en la forma "death by a thousands cuts" (es decir, cuando el conjunto de las agresiones es más grave que la suma de cada acto individual). En opinión de la Corte, se trataba de un caso en el que lo debatido era si la acción de la Administración había sido "excesiva" (too much), no inadecuada o ilegítima (what for) y que, dado que en situaciones de este tipo es difícil distinguir el "legítimo celo" de la Administración de la "presión ilegal",

100127 S. Ct. 2738 (2007). Amplios (y divergentes) comentarios en J. Harvie Wikinson III, "The Seattle and Louisville School Cases: There Is No Other Way", en 121 Harvard Law Review, 2007, págs. 158-183; Herbert K. GerkEn, "Justice Kennedy and the Domains of Equal Protection", Ibíd., págs. 103-130; James E. RYAN, "The Supreme Court and Voluntary Integration", Ibíd., págs. 131-157; el primero en favor y el resto críticos. Una perspectiva más general en MARTHA C. NussBAUMm, "Foreword: Constitutions and Capabilities: "Perception" Against Lofty Formalism", cit., págs. 5-97, especialmente, págs. 87-93.

101347 U.S. 483 (1954).

102 Chevron U.S.A. Inc. v. Natural Res. Def. Council, Inc., 467 U.S. 837 (1984).

103127 S. Ct. 1534 (2007)

104127 S. Ct. 2588 (2007).

105403 U.S. 388 (1971).

106127 S. Ct. 1534 (2007), p. 2594. 
no era posible establecer un estándar judicial claro, por lo que debía diferirse al Congreso la creación de posibles remedios frente a agresiones de este tipo. En último término, lo que el presente caso significa es un desplazamiento de la comprensión de estos casos del punto de vista de los derechos (la necesidad de que la Corte ofrezca algún remedio (en este caso, la indemnización) por violación de los derechos por parte del Gobierno Federal) al punto de vista de la división de poderes (la mayor adecuación del Congreso para establecer estándares indemnizatorios en dichas situaciones).

PENA DE MUERTE.

En Abdul-Kabir v. Quaterman ${ }^{107}$ y Brewer v. Quaterman ${ }^{108}$ (consolidados en Abdul-Kabir, 127 S. Ct. en 1663) el Tribunal analizó la constitucionalidad de dos sentencias de muerte en aplicación de la ley de Tejas que impone la pena capital cuando concurren (entre otras cosas) el carácter deliberado del acto y la peligrosidad futura, precluyendo la consideración de ciertas atenuantes. Aplicando Lockett v. Obio ${ }^{109}$ que obliga a tomar en consideración "como atenuante, cualquier aspecto del carácter o antecedentes del acusado y cualquier circunstancia del delito que el acusado alegue como base para una sentencia inferior a la capital", el Tribunal consideró que el Tribunal de Apelación Penal de Tejas (CCA) había inaplicado una "ley claramente establecida" y concedió el habeas corpus, anulando las sentencias y devolviéndolas al Tribunal a quo.

En Panetti v. Quaterman ${ }^{110}$ el Tribunal ha ampliado la doctrina de Ford $v$. Wainwright $^{111}$ en virtud de la cual la pena de muerte no puede imponerse a un acusado que se ha vuelto incapaz de comprender la conexión entre su delito y la ejecución, en aplicación de la Octava Enmienda, para incluir también a aquellos detenidos que pueden verbalizar dicha conexión pero que están tan alterados psíquicamente que son incapaces de entenderla racionalmente. Louis Panetti acabó con la vida de su esposa y la de los padres de ésta. Panetti defendió su caso vestido de cowboy y trató de citar como testigos a John F. Kennedy, al Papa y a Jesucristo. El Tribunal de Tejas lo condenó a muerte. La evaluación psiquiátrica del acusado mostró que aunque sabía que iba a ser condenado a muerte por su crimen, interpretaba dicha situación como un intento de impedirle predicar como parte de la batalla entre "los demonios y las fuerzas del mal y Dios y los ángeles y las fuerzas de la luz". 


\section{Cuarta ENMienda}

En Scott v. Harris ${ }^{112}$ el Tribunal estableció que el uso de medios violentos potencialmente mortales para acabar con una persecución automovilística no violaba los derechos de la Cuarta Enmienda. Harris circulaba a gran velocidad por una autopista en Georgia y, al ser detectado por la policía, trató de escapar cruzando líneas continuas y saltándose semáforos en rojo. Tras diez millas de persecución, el oficial Scout trató de poner fin a la persecución golpeando la parte trasera del vehículo de Harris con su parachoques delantero. El resultado fue un espectacular accidente del que Harris salió parapléjico. Harris presentó una demanda por uso de "fuerza excesiva" para detener su vehículo en violación de la Cuarta Enmienda, considerando la relativa insignificancia de su infracción de tráfico y la forma "controlada" en que había conducido su vehículo durante la persecución. Basándose, en parte, en una grabación en vídeo de la persecución, el Tribunal desechó su reclamación y fijó una nueva regla: "El intento de un oficial de policía de poner fin a una persecución peligrosa de un vehículo a alta velocidad que amenaza las vidas de transeúntes inocentes no viola la Cuarta Enmienda, incluso si coloca al automovilista que huye en riesgo de graves lesiones o de muerte".

\section{SEXTA ENMIENDA.}

Cunningham v. California ${ }^{113}$ pertenece a una serie de casos, inaugurada por Apprendi $v$. New Jersey ${ }^{114}$ que pretende aclarar la constitucionalidad de las normas sobre la fase de sentencia (que corresponde al juez) frente a la garantía constitucional de juicio por jurado. En Cunningham, el Tribunal anuló la Determinate Sentencing Law (DSL) de California que, para este caso, exigía imponer la sentencia de 12 años (no la de seis ni la de dieciséis) a menos que el tribunal encontrará un becho (o más de uno) agravante o atenuante, conforme a las principales pruebas. Lo que se discute en esta serie de casos es la posibilidad de que el tribunal imponga penas superiores a las que corresponden al delito, como consecuencia de agravantes que no han sido objeto específico de prueba y convicción ante el jurado.

Rita $v$. United States $^{115}$ pertenece a esta misma saga y puede llegar a tener una importante repercusión práctica aunque no introduzca grandes novedades jurídicas. Como es sabido, Booker declaró inconstitucionales las Federal Sentencing Guidelines por violación de la Sexta Enmienda ya que obligaba a los jueces a aumentar las sentencias por encima de lo probado ante los jurados. La solución a dicha decisión fue convertir dicha Guía en potestativa y no obli-

112127 S. Ct. 1769 (2007).

113127 St. Ct. 856 (2007).

114530 U.S. 466 (2000) y que prosigue en Blakely v. Washington (542 U.S. 296 (2004)) y United Sates $v$. Booker (543 U.S. 220 (2005)).

115127 S. Ct. 2456 (2007). 
gatoria. En Rita, el Tribunal declaró que los tribunales de revisión podían aplicar la presunción de razonabilidad en la revisión de sentencias que hubieran aplicado la Guía. El resultado de esta decisión bien podría ser que los tribunales inferiores adoptaran nuevamente la Guía como obligatoria para conseguir este estándar de revisión aligerado de sus sentencias. De hecho, según parece, desde el punto de vista sociológico, Booker no habría producido ninguna alteración en la duración de las sentencias impuestas ${ }^{116}$. La solución a esta decisión sería que el Congreso modificara la ley exigiendo una justificación detallada de la decisión de la sentencia por encima de la mera alegación de que se cumple la Guía (comportamiento que, de alguna manera, esta decisión del Supremo viene a autorizar). Ello convencería a los tribunales inferiores de que la Guía es, en verdad, potestativa y no obligatoria.

Utrecht v. Brown ${ }^{117}$ es otro caso en el que el Tribunal ha tratado de limitar la litigiosidad en torno a las penas capitales, insistiendo en la deferencia debida a los tribunales inferiores en estas materias (la Antiterrorism and Effective Death Penaltiy Act ${ }^{118}$ trató de obtener ese mismo resultado por vía legislativa). En Brown el Tribunal estableció que el Tribunal a quo no se había excedido en su capacidad de juicio al excluir a un jurado que había mostrado ciertas dudas ante la pena capital para el caso que se iba a juzgar, exclusión a la que la defensa no presentó objeciones. El jurado Z del Noveno Circuito declaró que, en su opinión, la pena de muerte era oportuna en los casos en que cabía esperar reincidencia. Informado de que la ley de Washington preveía la cadena perpetua sin posibilidad de libertad condicional para el homicidio en primer grado, manifestó que no podía imaginar una situación en la que la pena de muerte fuera oportuna pero que cumpliría la ley del Estado. El juez excluyó a dicho jurado. Posteriormente, Brown trató de lograr la revisión de su sentencia capital alegando la exclusión indebida del Jurado Z. El Tribunal Supremo consideró que el Tribunal a quo no está obligado a un razonamiento detallado, sino sólo a señalar las causas de exclusión y que, en todo caso, su valoración merece, en principio, deferencia ya que el Tribunal a quo está en mejores condiciones para juzgar la actitud general de los potenciales jurados a lo largo de toda la vista de selección.

Schiro $v$. Landrigan ${ }^{119}$ parece una muestra del excesivo formalismo que algunos comentaristas imputan a la Corte Roberts ${ }^{120}$. Landrigan condenado por homicidio en segundo grado y, posteriormente por la muerte de un interno en prisión, por evasión y un nuevo homicidio, rehusó en su último juicio la presentación del testimonio de su ex-esposa y de su madre biológica que le

116 Frank O. Bowman, III, «The Year of Jubilee... Or Maybe Not: Some Preliminary Observations About the Operation of the Federal Sentencing System After Booker, en 43 Hous. L. Rev. 279, 297 (2006).

117127 S. Ct 2218 (2007).

118 Pub. L. No. 104-132, 110 Stat. 1214.

119127 S. Ct. 1993 (2007).

120 Cf. Martha Nussbaum, "Foreword: Constitutions and Capabilities: "Perception" Against Lofty Formalism", cit., págs. 24 a 33, et passim. 
proponía su abogado, y que hubiera podido presentar circunstancias atenuantes. Posteriormente, Landrigan presentó un recurso alegando defectos en su representación procesal en un caso de pena capital. El Tribunal Supremo rechazó finalmente su petición razonando que había renunciado, en su momento, a la presentación de dichas pruebas. Lo que el Tribunal parece haber pasado por alto es que el acusado no renunció a cualquier posible testimonio atenuante, sino a los dos que su abogado le propuso (es relativamente frecuente que los acusados de pena capital se nieguen a involucrar en sus juicios a sus familiares cercanos) y no a otros que, de haber realizado aquél correctamente su tarea, podría (y debería) haberle propuesto.

\section{DeBIDO PROCESO.}

Gonzales v. Carhart ${ }^{121}$ es, sin duda, una de las decisiones más polémicas tanto en el fondo como en la forma del presente ejercicio. En ella, el Tribunal sostuvo la constitucionalidad de la Partial-Birth Abortion Ban Act de 2003. Dicha ley prohíbe una determinada técnica de interrupción del embarazo (el aborto por parto parcial) sin excepción alguna para el posible riesgo para la madre (indicación terapéutica). Aunque Planned Parenthood of Southeastern Pennsylvania $v$. Casey ${ }^{122}$ impuso la obligatoriedad de la excepción del riesgo para la vida de la madre a cualquier prohibición del aborto, el Tribunal consideró que dado que las opiniones médicas son contradictorias sobre si existe algún caso en que esta concreta técnica sea necesaria para salvaguardar la salud de la madre, debía declarar la constitucionalidad prima facie de la norma, aunque dejaba abierta la posibilidad de impugnar actos concretos de aplicación en los que dicha necesidad pudiera demostrarse. En definitiva, el Tribunal está admitiendo la constitucionalidad de normas que podrían violar los derechos de las mujeres, aunque no es seguro que lo hagan. Justamente, la forma de proceder contraria a la que suele aplicarse en casos de derechos fundamentales. Aunque el Tribunal ha declarado el derecho al aborto terapéutico, ahora declara la constitucionalidad de una norma que prohíbe abortos que podrían responder a dicha clasificación. Más allá de la dudosa técnica de declarar constitucional una ley porque podría no violar los derechos de una persona, reaparecen en la sentencia algunas consideraciones típicas de la propaganda antiabortista - y totalmente ajenas a la cuestión debatida (la obligatoriedad de la excepción terapéutica) — con notables tintes de machismo y paternalismo del tipo: "Aunque no bemos podido encontrar datos fiables para medir este fenómeno, parece inatacable la conclusión de que algunas mujeres llegan a arrepentirse de su decisión de abortar esa vida infantil que una vez engendraron y mantuvieron" ${ }^{123}$. 
Philip Morris USA v. Williams ${ }^{124}$ es un nuevo caso del paradójico uso que los Tribunales han venido haciendo de la Decimocuarta Enmienda. Aprobada como golpe de gracia a la esclavitud y como promesa de igualdad de derechos para los afro-americanos, el Tribunal declaró en 1873 que "Mucho dudamos que acción alguna de un Estado que no se dirija discriminatoriamente contra los negros como clase, o en atención a su raza, llegue a ser nunca considerada como afectada por esta disposición" ${ }^{125}$. Sorprendentemente, en cambio, la Enmienda se ha convertido en el valuarte de defensa de las grandes corporaciones frente a las reclamaciones de indemnización. En Philip Morris el Tribunal Supremo anuló una condena a la tabacalera Philp Morris inicialmente de 79,5 millones de dólares, reducida después a 32. El Tribunal Supremo sostuvo que debía anular la condena porque se había permitido que el jurado tomara en consideración daños a personas distintas del reclamante (Williams). Aunque los daños a otros miles de personas pueden afectar a la "reprensibilidad" de la conducta, no pueden servir directamente para la determinación de la indemnización. Esta distinción ad hoc creada para este caso provocó, entre otras cosas, el entusiasmo de los lobbies ${ }^{126}$ y una enérgica crítica del editorialista del New York Times: "Hace décadas que los miembros más privilegiados de la sociedad —las empresas, los ricos, los blancos que desean asistir a clase con otros blancosno disfrutaban de un año judicial en el Tribunal Supremo tan satisfactorio" ${ }^{127}$.

LIBERTAD DE EXPRESIÓN.

FEC v. Wisconsin Right to Life (WRTL), Inc. introduce sustanciales modificaciones en la regulación de la financiación privada de las campañas políticas. En McConnell ${ }^{28}$, el Tribunal declaró la constitucionalidad prima facie de la Bipartisan Campaign Reform Act de 2002 (BCRA) ${ }^{129}$ que consideraba delito que las corporaciones o sindicatos emplearan fondos generales para pagar "Comunicaciones electorales". WRTL, en cambio, ha declarado la inconstitucionalidad de la aplicación de la norma en un caso concreto, invirtiendo, en la práctica, el estándar anterior, aunque sin revocar formalmente el precedente (lo que hubiera resultado inusual en una decisión con menos de cinco años de antigüedad). Así, mientras que McConnell prohibía cualquier anuncio que "razonablemente entendido fuera más allá de una discusión de las cuestiones (es decir, que pudiera ser entendido como propaganda electoral)", ahora se autorizan todos los que (incluso haciendo uso de considerable imaginación) puedan ser entendidos como algo distinto de una petición electoral. Es decir,

124127 S. Ct. 1057 (2007).

125 The Slauther-House Cases, 83 U.S. (16 Wall.) 36, 81.

126 "It's our best Supreme Court ever", cfr. LINDA GreEnHouse, "In Steps Big and Small, Supreme Court Moved Right, en New York Times, 1 de julio, 2007, p. A18.

127 "Justice Denied", en New York Times, 5 de julio, 2007, p. A12.

128 540, U.S. 93.

1292 U.S.C. \ 434 (f)(3)(A)—(C) (2000 \& Suppl. IV 2004). 
parece volver la así llamada técnica de las "palabras mágicas" ('voto', 'votar', 'candidato', etc.), únicas susceptibles de provocar la ilicitud de los anuncios tal como, antes de McConnell, establecía Buckley $v$. Valeo ${ }^{130}$. Esta sentencia llega puntualmente a la campaña presidencial del 2008.

Morse v. Frederick ${ }^{131}$ introduce una nueva limitación a la libertad de expresión en las escuelas por parte de los estudiantes. Tinker $v$. Des Moines Independent Community School District ${ }^{132}$ declaró ilegal la prohibición de llevar brazaletes negros en clase como protesta contra la Guerra de Vietnam, razonando que sólo podían prohibirse los usos de la libertad de expresión en las escuelas que provocaran una "alteración sustancial o una interferencia importante" en las actividades escolares. El Juez Fortas afirmaría que los estudiantes no "dejan su derecho constitucional a la libertad de expresión en la puerta de la escuela". Dos decisiones posteriores introdujeron algunas limitaciones: la prohibición del lenguaje indecente ${ }^{133}$ y la posibilidad de controlar los periódicos sufragados por la escuela "en una forma razonable" ${ }^{134}$. Frederick añade, ahora, la prohibición de la promoción del uso de drogas ilegales.

\section{Doctrina ChEVRon.}

Zuni introduce una aparentemente pequeña modificación en la doctrina Chevron pero que podría convertirse en un importante giro interpretativo. Como es sabido, Chevron exige, primero, analizar el texto en búsqueda de la intención del Congreso expresada en un lenguaje no ambiguo y, después, el análisis de la finalidad y antecedentes de la decisión. En Zuni, en cambio, el Tribunal ha procedido, primero, a determinar la finalidad y antecedentes y, a la luz de éstas, ha examinado la ambigüedad o no del texto legal. Como es fácil deducir, dado el carácter más discutible de "finalidad y antecedentes", basta atribuir algún sentido a los mismos para, después, alegar la ambigüedad del texto (en realidad, incompatibilidad) superando ambos pasos. En definitiva, parece apuntar aquí una corrección al enfoque "textualista" que subyace a Chevron en favor de una interpretación "intencionalista" del tipo que se manejaba en (el revocado) Church of the Hoy Trinity v. United States ${ }^{135}$, conforme al cual una disposición incluida en el texto pero no en la intención de la ley, no forma parte de la misma.

Nacional Ass'n of Home Builders $v$. Defenders of Wildlife $e^{136}$ amplía, por su parte, el alcance de Chevron. Chevron surge del reconocimiento de que las disputas acerca del acierto de las decisiones públicas y la resolución de las lu-

130424 U.S. I, 77 (1976).

131127 S. Ct. 2618 (2007).

132393 U.S. 503 (1969).

133 Bethel Sch. Dist. No. 403 v. Fraser, 478 U.S. 675 (1986).

134 Hazelwood Sch. Dist. v. Kublmier, 484 U.S. 260 (1988).

135143 U.S 457 (1892).

136127 S. Ct. 2518 (2007). 
chas entre visiones alternativas del interés público no tienen carácter judicial. Por ello, cuando el Congreso aprueba legislación ambigua delega su autoridad sobre el establecimiento de las políticas a las agencias encargadas de aplicarlas. Home Builders amplía esta delegación al caso de leyes no sólo ambiguas, sino directamente contradictorias.

Massachusetts $v$. EPA ${ }^{137}$, en cambio, apunta a un intento de control de ciertas decisiones de las Agencias, en este caso, en materia ambiental. La Agencia de Protección Ambiental (EPA) había rechazado una petición de diecinueve agrupaciones privadas en la que le solicitaban que regulara las emisiones de gases de efecto invernadero de los vehículos de motor nuevos. La EPA argumentó que carecía de competencia para regular sustancias como el dióxido de carbono ya que no serían "contaminantes del aire". Dichas organizaciones junto con algunos estados recurrieron su decisión. El Tribunal Supremo concedió legitimidad activa a los estados por su interés cuasisoberano (parens patriae) y estableció que la regulación del dióxido de carbono caía bajo la competencia de la EPA y que ésta no podía negarse, por tanto, a ejercer sus funciones regulatorias.

\section{DERECHO A LA EDUCACIÓN.}

Parents Involved in Community Schools v. Seattle School District No. $1^{138}$ se ocupa de dos planes de integración racial en las escuelas, adoptados voluntariamente en Seattle (Washington) y Jefferson (Kentucky). Seattle nunca fue objeto de una orden judicial de desegregación racial, pero adoptó un programa obligatorio de transporte en autobús de estudiantes en 1978. En 1988 sustituyó dicho programa por otro que permitía a los estudiantes elegir escuelas con ciertas restricciones de base racial. En 1999 se puso en marcha una clasificación en blanco y no blanco, que servía para determinar la admisión a ciertas escuelas muy solicitadas pero cuya ratio blancos/no blancos quedaba fuera de una franja en torno a la media estatal. Tras un año de permanencia, el cambio de escuela se operaba sin consideración a la raza.

Jefferson, en cambio, fue objeto de un plan judicial de desegregación en 1975, que incluía el trasporte obligatorio en autobús. Posteriormente se sustituyó por otro que, una vez suprimida la orden judicial en 2001, establecía que los nuevos estudiantes señalarían sus preferencias entre un grupo de escuelas cercanas a sus casas, asignándoseles la preferida salvo que no dispusiera de vacantes o si dicha asignación provocaba que el porcentaje de estudiantes negros cayera por encima del 15 o subiera por encima del 50 por ciento.

El Tribunal Supremo consolidó ambos casos anulando los dos planes. El Presidente Roberts, como ponente, dispuso que estos planes suponían una clasificación racial que violaba la Cláusula de Igualdad a menos que estuvie- 
ra "estrechamente adaptada" a la consecución de un "interés gubernamental prioritario". Según el Presidente Roberts los intereses que figuraban en la jurisprudencia vigente eran "remediar los efectos de la discriminación intencionada anterior" y la "diversidad en la educación superior". En su opinión, no se había probado que Seattle hubiese estado jurídicamente segregada en ningún momento ni sometida a órdenes judiciales de desegregación, mientras que Jefferson había logrado el status unitario, remediando así pasadas discriminaciones. El segundo tampoco se daba porque la raza figuraba en estos planes no como parte de un esfuerzo por conseguir un ambiente con variedad de personas, culturas, ideas y puntos de vista, sino como factor decisivo. Se introduce, pues, una distinción entre discriminación de iure y de facto para la legitimidad de los planes de desegregación.

Las reacciones a esta decisión han sido explosivas, tanto dentro de la Corte (entre la minoría) como en los medios de comunicación ${ }^{139}$. Aunque la Corte ha tratado de presentar su opinión como consistente con Brown, la mayor parte de los comentaristas coincide en que se trata de un duro golpe a las políticas de integración racial.

En Winkelman v. Parma City School District ${ }^{140}$ el Tribunal ha reconocido la capacidad de los padres de representarse a sí mismos en las impugnaciones de los Programas de Educación Individualizada (IEP) de sus hijos de la Individuals with Disabilities Education Act ${ }^{141}$. Ello supone, en definitiva, la posibilidad de concurrir sin abogado, lo que resulta esencial para la viabilidad práctica de la norma entre las familias menos acomodadas.

\section{DISCRIMINACIÓN LABORAL.}

En Ledbetter $v$. Goodyear Tire E Rubber Co. ${ }^{142}$ el Tribunal rechazó una demanda de discriminación salarial contra una mujer, porque los actos incluidos en el período de 180 días que la ley marca para la demanda no eran por sí mismos discriminatorios, aunque sí lo eran considerada la historia laboral de 20 años de la demandante. Esta decisión introduce una importante limitación a este tipo de demandas que, por su propia naturaleza, suelen referirse a diferencias incrementales y acumulativas a lo largo de muchos años (en este caso, ella cobraba, al final de su vida laboral, 3.727 dólares, mientras que los hombres en idéntica posición cobraban entre 4.286 y 5.236 dólares) y no a actos singulares de discriminación, lo que dificulta la percepción por parte de

139 El Juez Breyer, por ejemplo, afirmó que se trata de una decisión de la que «la Corte y la Nación llegarán a arrepentirse", el Juez Stevens que "[tengo] la firme convicción de que ningún miembro de la Corte a la que me incorporé en 1975 habría estado de acuerdo con la decisión"; el New York Times en su Editorial, "no debe quedar ninguna duda de la radicalidad de esta decisión" ("Re-segregación ahora", 29 de junio, 2007, p. A26), etc.

140127 S. Ct. 1994 (2007).

14120 U.S.C. \$\$1400-1482 (2000 \& Supp. IV 2004).

142127 S. Ct. 2162 (2007). 
las perjudicadas de que la discriminación existe y hace muy difícil construir un caso irrefutable de discriminación en un período cualquiera de 180 días.

ABSTRACT.- This Article provides a broad-lens, synoptic perspective on war-on-terrorism questions within the constitutional actuality in the United States and a summary of Supreme Court's leading cases in 2006-2007 terms. The central claim is that the Military Commissions Act of 2006 raises serious problems for any liberal view of the Constitution and is inconsistent with the reach of constitutional guarantees as they have been defined in cases arising from the war on terror. We also discuss a recent D.C. Circuit decision in which the court upheld the jurisdiction-stripping provision on the ground that it is consistent with both the scope of habeas corpus at common law as well as supreme Court precedent. 